\title{
An Analysis on the Children in Early Childhood with Autism Spectrum Disorder in North Sulawesi
}

\author{
Jeane Marie Tulung ${ }^{1}$, Olivia Cherly Wuwung ${ }^{2}$, Febri Kurnia Manoppo ${ }^{3}$ \\ Institut Agama Kristen Negeri Manado, Manado, Indonesia \\ \{jeane.tulung@iakn-manado.ac.id ${ }^{1}$, olivia.wuwung@iakn-manado.ac.id², \\ febrimanoppo@iakn-manado.ac.id $\left.{ }^{3}\right\}$
}

\begin{abstract}
A child in early childhood with Autism Spectrum has a condition of impaired development of brain function (nerve cells of the brain) that can affect almost all aspects of individual development. These symptoms initiate at an early childhood. A child in early childhood with autistic spectrum has challenges all physically, psychologically, and socially to survive both in the family and school environment in this disruptive era. This fact is happened in several Christian schools which are special schools that manage children with autism spectrum in Manado and surrounding areas. This study aimed to describe the resilience factors of children in early childhood with ASD in disruptive era at some special schools for ASD in North Sulawesi. The writers used the resilience theory of Reivich and Shatte in analyzing the resilience factors occurred. This study used qualitative approach with data triangulation through the methods of observation, interviews, and documentation studies. This study was conducted from October to December 2019. The result showed that the resilience of children in early childhood with ASD was happened in the increase of positive aspects of attitude caused by some things, namely; performing a routine theraphy; partnership with parents in applying the ABA method; the power of empathy and interaction; explorative and functional games; the humanistic, religious, and contextual inclusive pedagogic model; and the visualization aspects.
\end{abstract}

Keywords: Resilience Factors, Children in Early Childhood, Autism Spectrum, Disruptive Era.

\section{Introduction}

Autism Spectrum Disorder is a developmental condition that is recognized at the beginning of life and continued to be proven over the lifetime of the individual. It is called spectrum disorder because there are various symptoms following and also there is an intensity range. There exist various differences of severity for ASD depended on the severity levels including symptoms, age, chronology and the development level of each person with ASD [1].

Autism Spectrum Disorder (ASD) is seen in various cognitive abilities; some people with ASD have learning disabilities accompanying (about $50 \%$ of people with ASD have learning disabilities) whereas the others only have average intelligence or above average. However, everyone with autism spectrum has the same problem with their behaviors namely their social abilities, empathy, flexibility, and communication which are clearly different in spite of the extraordinary variations from person to person.

ASD is often described in terms of 'Dark Triad', which describe a series of major difficulties such as: 
a) Difficulties in social interactions. People with ASD will find it difficult to understand others' emotions and perspectives, hence their response may be unpredictable, confusing or appear like selfish. They also may seem distant and uninterested in social approaches.

b) Difficulties with verbal and non-verbal communications. People with Autism Spectrum Disorder are difficult to understand the nuances and the delicacy of both verbal and nonverbal languages. Communication can present problems or cause real problems leading to misunderstandings and even the worst leading to social isolation.

c) Difficulties with his own imagination. People with ASD definitely experience difficulties to predict what might be happened and to think about the social consequences of certain situations, making mistakes, misunderstandings and potential crises. Generally, they tend to concentrate more on details, even on the small things of the whole picture. These difficulties are often accompanied by the following things:

d) Repeated behavior. People with ASD will repeat certain words or activities, or it can be said that they 'stuck' on a subject or idea. Their lives are seemed controlled by the unchangeable routines.

e) Sensory sensitivity. It is a significant sensitivity to anything from various angles of vision, sound, touch, and motion, and it can be very weakening. These main points will be seen clearly in the individual's developmental history, although some difficulties probably can be covered by compensation or support [2].

Children with ASD usually do not have the ability to recognize emotions on other people's faces and they also do not know how to reflect those emotions either. Emotional reactions on the changes can be a major concern for children with ASD. The characteristic of children with ASD is that they do not like changes. They adjust themselves to the status quo of the daily schedule and feel secure in intimacy. They often do not notice the surrounding environment, and so on. They are often surprised by unexpected events. Changes are unsettling matters, they often cause fear, and eventually they can cause behavioral reactions. Children with ASD can continue to associate fear with the presence of certain objects or events (people or places) long after a child experiencing them. Fear can turn into frightening memories which will later become the reason for recurring disorders.

The writers conducted initial observations at several Christian schools that specifically accept children in early childhood with ASD. The observations showed that some students with ASD attend school as usual, perform routine therapy, and participate in inclusive learning programs in the school. Some parents and caregivers expressed the difficulties during taking care of these children. There are some caregivers talking about how difficult it is to interact at the beginning of the caring and to train the children focus. There are also parents who less concern with the emotional needs of the children. Many parents lack in providing special time to educate and to take care of their children. Disruptive era also provides special challenges for teachers, parents and caregivers. The rapid development of information technology also emerges the digital products such as gadgets, laptops, and other digital devices. The technological development added with the easy access of all information through social media that makes it is easier for every individual to connect globally. The things mentioned above also affect the way of the children in early childhood with ASD to survive. How is the resilience of the children in early childhood with ASD in disruptive era? The writers used the Reivich and Shatte resilience theory to analyze the resilience factors occurred. 


\section{Research Method}

This study applied qualitative approach and the techniques of data collection are triangulation of the observation data, interviews, and documentation studies. The collected data were analyzed to be concluded. This study was conducted in October to December 2019 at SLB Permata Hati, AGCA Center, and Hizkia school, an Inclusive Kindergarten in Manado, North Sulawesi province.

\section{Result and Discussion}

\subsection{Performing Routine Therapy}

The digitation of information lay the foundations of changes in lifestyle and attitudes of parents from nurturing children at home to an institution. They seem to lay the blame for parenting responsibilities on the teachers at schools and on the special caregivers. Some parents are starting to take a meager role in nurturing children with autism spectrum disorders. Therefore, based on the observations at the research location, the children in early childhood with Autism Spectrum Disorder are necessarily needed an intense treatment, in this case a periodic therapy. Periodic therapy will enable the childen to stay calm. With therapy children can clearly say their wishes for example in terms of food selection. Although it is still in a limited amount and medium intensity, it becomes one of resilince factors for ASD children. It was said by one of the caregivers of the ASD children in the interview [3]. Due to this, children with ASD (Autism Spectrum Disorder) also show development in terms of the number of words that can be absorbed. This era of disruption allows the therapists of children with ASD to make new breakthroughs such as involving technology in providing the therapy. It needs synergy between parents and teachers, so that these therapeutic activities become neatly scheduled and also parents' concern for the children progress and development.

\subsection{Developing Positive Parenting Pattern}

Generally, children with ASD (Autism Spectrum Disorder) experiencing retardation in the development of their brain cortical network which is resulted in their ability to control emotions and other things. It causes the child development delayed for several years. When the children are in that situation and condition, they need us to support them and encourage them with opportunities for emotional and social developments. A simple strategy in helping children find the right playmates who may be younger than him and are in the same development stage. When a child with ASD (Autism Spectrum Disorder) is hyperactive or impulsive, he may become less attentive to his own internal emotional state. Consequently, it is possible to be failed in learning the existing emotional condition. The child may be emotionally immature [4]. We can support him by using positive parenting pattern, educating attentively, and applying mentoring techniques relevant to the children developmental stage.

\subsection{Understanding Their Emotional Regulation with the Ability of 4.0 Digital Media.}

Anxiety is a major problem for children with ASD (Autism Spectrum Disorder). Anxiety can be from various sources, namely: 
a) Social anxiety or social immaturity of the child to be in public environment;

b) Stress originated from personalities such as perfectionism;

c) External stressors of the child such as poor grades, being bullied, and being overawed. Children feel uncomfortable and disturbed;

d) Reactions to food sensitivity, including colorings and additives. Certain types of food are indeed not good consumed by children with ASD (Autism Spectrum Disorder)

e) Family conditions such as moving house, moving school, moving place, divorce, unemployment parents or losing jobs [5].

Some of those problem sources causing the child to continue experiencing anxiety. The high levels of anxiety make it more difficult for the child to face other emotions which arise for these complex problems. Overall, the weak emotional regulation will affect the child ability to overcome their social problems. Things that can be happened in the twisted social situation are the anxiety increasing and given greater opportunities to be more developed in children. In addition, it can cause stress which is a child predisposition to fighting or running patterns. This behavior can trouble him to maintain a positive disposition. Consequently, he can develop madness behavior, negative dispositions, resentful and other negative emotions [6].

The importance of early treatment and understanding of emotional tendency on children with ASD (Autism Spectrum Disorder) enable us to overcome and to learn the ways of stabilizing each of their anxiety. The management can be through online methods or online learning with digital learning media. According to the writers, the parents, the teachers, and the caregivers can utilize the information access of how to regulate children emotions. The development of information technology brings positive impact in providing easy access for information about parenting pattern and methods of assisting children with ASD. The teachers and the parents can guide the ability of children in early childhood who are interested in digital technology. Based on the interview with one of the teachers of Hizkia School Manado, "there are students interested in using digital learning devices at home, these children look smart cognitively, however they need assistance so that they can interact with others" [7]. Those things indicate that both teacher and parents can utilize the information technology developments to help children regulating their emotions. Teachers assist children in increasing positive aspects at school, and parents provide adequate time to assist their children at home.

\subsection{Partnership with Parents}

The ABA (Applied Behavior Analysis) method is widely considered as one of the best ways to nurse children and adults with ASD. It gives solutions for teachers, ABA therapists, parents, and everyone involved with ASD children. ABA is a method needed to change behavior. Managing the behavior of children with ASD is the beginning of their education. Most parents ask for the children with ASD to be trained and familiarized with behavior education. It is because the children with ASD tend to have abnormal behaviors. They are still uncontrollable and disobedient. Cooperation is needed in the partnership of the parents and the children with ASD. By applying the ABA method both at school and at home, the child will definitely get used to and start learning to be obedient. Teachers are expected to socialize ABA methods that may be understood by parents and performed by themselves at home. ABA stands for applied behavior analysis. $\mathrm{ABA}$ is a scientific approach to evaluate and change behavior which is supported by many years of research findings and analysis. ABA also focuses on increasing the significance of social behavior to a meaningful level; it roots on behavioral principles such as 
positive reinforcement and extinction, and utilizes systematically the behavior change tactics; it targets the behaviors which can be observed, measured, and driven by data [8]. "Parents whose children attend this school are asked to teach with the same pattern as applied by the teachers[9]".It is intended for children to continue receiving ongoing care not only at school.

\subsection{School for All}

Children with ASD need to go schooling, of course at schools which are succeeded in educating children with ASD (Autism Spectrum Disorder). What kind of school is suitable for children with ASD? It is the school capable of being learning partner for children with ASD (Autism Spectrum Disorder). The school should have a clear vision to create a safe, calm, friendly, and conducive environment for student learning and welfare. The school is not merely intended as a commercial business. The school asks the teaching staff to treat parents and children with respect and fairness. This egalitarian education needs to be considered and to be well thought according to education philosophy. In fact, in the current Educational development, the roles of homeroom teachers and supporting staffs are more likely the salesmen selling education only as a competition product with the neighboring schools.

The suitable school for children with ASD never forgets the individuality and diversity of all the students. For this reason, the school provide the needs of the teaching staffs to independently and positively reflect on themselves. Therefore, the teaching staffs are encouraged to not questioning things involving unrealistic prejudices, demands and visions. It aims to enable each student developing their full academic potential independently and personally obtain the life skills needed socially. In the end, in the suitable school for children with ASD, every student, parent, teacher, supporting staff, and everyone involved is treated and appreciated as human being.

The teachers, the teaching staffs, and the school founders are the key to the education of the happy and successful children who mostly view the world from a very different perspective. They also help the parents and the caregivers because they are related to the general needs of children with ASD at home and in their playing environment. One of the most important things is the school to be supported by the parents at home. The school needs to work cooperatively and collaboratively as well as to have good intentions based on the mutual respect [10].

In this case, the writers found out that all parents or guardians and professionals must not blame and accuse each other. As humans with good intentions, all work towards the availability of the best education for children with ASD (Autism Spectrum Disorder). Everyone must be burdened with responsibility. In addition, as written by Henry David Thoreau, when the young people walked there was a 'different drummer' beat: not to be healed but to be activated inspired by educational experiences of children with ASD (Autism Spectrum Disorder) [11]. The suitable school for serving all children with ASD will be aware of the common causes of their stress and suffering. That school will give each child the feeling of being in the place where they belong to.

\subsection{Praising Wholeheartedly}

Praise holds an important part in proactive approach [12]. The most underestimated characteristic of autism is 'the rigid thinking'. During the study, the writers observed that many children quickly developed routines and behavioral sequences which must be obeyed. Thus, the writers concluded that 'the rigid thinking' was the main force behind the most challenging behavior. It can emerge from a single event where the nature of autism is self-centered. The 
rigid thinking has established it as a necessity. For example, when learning with others, a child with ASD may show impatience and frustration. The more it is repeated, the greater the behavior is strengthened and quickly decided [13].

\subsection{Caring Teacher}

The sincere affection given by the teachers will make the children with ASD respond to each of their commands. Children with ASD will surely find difficulties to convey their desires. However, they also have the drive to look after people who care about them. Based on the observations at TK Hizkia School and at TK Permata HatiAutis Manado, it is showed that there are certain teachers who are easily understood by the children both in verbal and nonverbal communications. The children are quite fond of them. The caregivers and the parents who are loved by the children will help them learning positive behavior [14]. It illustrates that teacher care is needed in improving the positive aspects in terms of social and emotional development of the children.

\subsection{What Said by the Teachers, the Therapists and the Parents will Help Them Survive in Interaction}

Indeed children with ASD are known to have disabilities in social interaction. Nevertheless, having disabilities does not mean they are unwilling to interact. Because in fact, what the teachers, the therapist and the parents say repeatedly will be finally listened and obeyed [15]. Based on the results of the study, the children with ASD were able to understand the teacher's comands, and to obey the repeated commands of the teachers. It was stated by the teachers who educate the children with ASD [16]. Disruptive era enables teachers and parents to access parenting pattern information through the usage of digital learning media.

\subsection{Verbalization and Communicative Movement}

When an autistic child is playing, the child will ramble and scream. The teacher then responds to the child's behavior for example when the child is playing blocks and the blocks are fell, the teacher shouts "Blocks falling" [17]. It will then cultivate the children basic abilities. With the teacher's response, the child will be able to practice basic skills. Then the child will understand how to convey what they want when the teacher says "please take the bottle" and gives the bottle. The visual learning of ASD presents verbalization and communicative movements.

\subsection{Explorative and Functional Games with Toys}

Some explorative games can be tried by teachers and parents to improve the positive aspects as a one of the factors of children resilience. One method that can be applied is by playing roles. This activity can use toys that can stimulate their thoughts and emotions. Pretending to play with toys for example dolls. When the teacher instructs to rest (sleep) then the doll will be arranged or positioned as the teacher said [18]. Hereby, the autistic child sees the picture of sleeping [19]. Actually, Children with ASD are able to mimic what they usually see. The truth is the routine activities encouraging them to experience an increase in positive aspects that they are able to pay attention to details although it is not the whole contents of the image. Some children with ASD begin to like singing, they imitate these things from TV shows, Youtube, social media everyday where they live [20]. This era of disruption provides room for children 
with ASD to have resilience. It is because ASD children also enjoy the development of the present technology although they cannot focus on one thing.

\subsection{Educational Relevance for Children with ASD (Autism Spectrum Disorder)}

The writers view the need of developing inclusive pedagogy which is humanist, religious, and contextual in increasing the resilience ability of children in early childhood with ASD especially in Manado and the surroundings. "Most of schools specifically accepting students with ASD are mostly located in Manado, while the need for school institutions which are able to actualize the inclusive education focusing on dealing with children with ASD is quite a lot [21]". In North Sulawesi, the need of inclusive education which is able to handle the children with ASD is still hampered with the lack of facilities and attention from stakeholders. Why do we need inclusive pedagogy? Because the inclusive pedagogy states that all children are capable as learners. Inclusive education requires changes in teachers, in this case the beliefs, attitudes and knowledge, especially in the context of learning. Such view is so much in harmony with the perspective of children with ASD on education and prioritizing teacher understanding and environmental adaptation. The important issues for education related to students with ASD are explained in relation with the role of communication in teaching. Dynamic experiments in pedagogy are considered very important to rethink the way of managing behavior for students with ASD. Furthermore, teacher professionalism with the existing professional standards is very important. All considerations of inclusive education requires clarity namely, the relationship between education and therapy. It has long been one and has taken an important role for years. The ancient Greeks for example considered education as part of investigation which could be used to heal people with personal illnesses.

In modern era, educational therapy is a term that has been used to describe a learning approach focused on developing students' ability to study. All students are supported by the teachers in their capacity to study, namely attendance in the learning process and to identify what is important in learning, to process, to organize and to remember information [22]. According to the writers, the humanistic inclusive pedagogical models will be able to provide a sense of security to the students. Religious pedagogy will be able to form the affective and spirituality aspects of the children. Whereas, the contextual inclusive pedagogy will make it easier for teachers, therapists, caregivers and parents to adjust the learning process with learning media available both at school and at home.

\subsection{Visual for children with ASD}

Imitation is the essence of learning for children with ASD (Autism Spectrum Disorder). The activity of modeling certain games and social behavior for children to be imitated will further strengthen the imitating behavior. Teachers and parents need to understand how to present learning materials for children with ASD. There are many children with ASD (Autism Spectrum Disorder) who are much better as visual learners. Whatever the type, children will learn "Better" if the material is presented visually. Children with ASD (Autism Spectrum Disorder) tend to be smart in visual-based skills and are not good at verbalbased skills [23]. It showed that both teachers and parents need to understand the importance of visualization models in learning of children with ASD. If it is considered, it will bring positive impact in resilience aspect of children with ASD. 


\section{Conclusion}

The resilience of the children with ASD (Austism Spectrum Disorder) occurs in increasing positive aspects of behavior which are due to several things, namely:

a) Performing routine therapy. A routine theraphy allows children with ASD (Austism Spectrum Disorder) to increase positive aspects.

b) Partnership with parents in the application of the ABA method for children both in school and at home through therapy or other habituation programs by the teachers, the parents and the caregivers.

c) Caring Teachers, the power of empathy from teachers, caregivers, and parents will be able to grow positive aspects in children behavior.

d) The increase of positive aspects of children with ASD (Austism Spectrum Disorder) is also closely related with interaction in conversation form which can be performed by the teachers, the therapist and the parents. What said by the teachers, the therapist and also the parents will help them survive in interaction

e) Explorative and Functional Games with Toys become tools of theraphy which are able to explore the ability and the focus of children with ASD (Austism Spectrum Disorder)

f) Relevant education such as the humanic and contextual inclusive paedagogic model for children in early childhood with ASD.

g) Learning which maximizing visual aspect for children in early childhood with ASD enables the emergence of imitating behavior which can increase the positive aspect.

\section{References}

[1] Penny Morgan, Child Protection \& Parents With A Learning Disability, London N1 9BE, UKand 400 Market Street, Suite 400, 2017. Pg.94

[2] Penny Morgan, Child Protection \& Parents With A Learning Disability, London N1 9BE, UKand 400 Market Street, Suite 400, 2017. Pg.91-93

[3] Interview with Ms. Henny Sampelan, AGCA Center, on November 08, 2019

[4] Theresa Garland, MOT,OTR, Self-Regulation Interventions and Strategies, Keeping the Body, Mind and Emotions on Task in Children with Autism, ADHD or Sensory Disorders, United States of America, 2014, ISBN: 978-1-936128-77-8, Pg.136

[5] Dr Catherine Harvey, Difference not Disorder, Understanding Autism Theory in Practice, 73 Collier Street London N1 9BE, UK And 400 Market Street, Suite 400 Philadelphia, PA 19106 , USA, 2018, ISBN 978178592 4743, Pg. 31

[6] Dr Catherine Harvey, Difference not Disorder, Understanding Autism Theory in Practice, 73 Collier Street London N1 9BE, UK And 400 Market Street, Suite 400 Philadelphia, PA 19106, USA, 2018, ISBN 978178592 4743, Pg. 32

[7] Interview with Ms. Nancy, Hizkia School, on November 10, 2019

[8] Elle olivia Johnson, Orangtua Panduan Untuk Di rumah ABA program Pertanyaan tentang analisis masalah terapan sering meminta anak Anda dengan autisme, London, 2013, Pg.20

[9] Interview with Ms. Nancy, Hizkia School, on November 10, 2019

[10] Dr Catherine Harvey, Difference not Disorder, Understanding Autism Theory in Practice, 73 Collier Street London N1 9BE, UK And 400 Market Street, Suite 400 Philadelphia, PA 19106, USA, 2018, ISBN 978178592 4743, Pg. 121

[11] Dr Catherine Harvey, Difference not Disorder, Understanding Autism Theory in Practice, 73 Collier Street London N1 9BE, UK And 400 Market Street, Suite 400 Philadelphia, PA 19106, USA, 2018, ISBN 978178592 4743, Pg. 119,148 
[12] Dr Catherine Harvey, Difference not Disorder, Understanding Autism Theory in Practice, 73 Collier Street London N1 9BE, UK And 400 Market Street, Suite 400 Philadelphia, PA 19106, USA, 2018, ISBN 978178592 4743, Pg. 120

[13] TERESA GARLAND, MOT, OTR, Self-Regulation Interventions and Strategies, Keeping the Body, Mind and Emotions on Task in Children with Autism, ADHD or Sensory Disorders, 3839 White Ave Eau Claire, WI 54703 Printed in the United States of America, 2014, ISBN: 978-1936128-77-8, Pg.127

[14] Gazi F Azad, Sara Gormley, Steve Marcus, David S Mandell, Parent-teacher Problem Solving about concerns in children with autism spectrum disorder: The role of incomwe and race, Psychology in the Schools 56 (2), Pg. 276-290,2019

[15] Marjorie H Carlop, Russell Lang, Mandy Rispoly, Keterampilan Bermain dan Sosial untuk anakanak dengan gangguan autis, ISSN 2366-6013, Praktek Berbasis Bukti dalam Kesehatan Perilaku, 2018, Pg.26

[16] Interview with Ms. Nancy, Hizkia School, on November 10, 2019

[17] Marjorie $\neg$ H. $\neg$ Charlop Russell $\neg$ Lang Mandy $\neg$ Rispoli, Play and Social Skills for Children with Autism Spectrum Disorder, Psychology Department Claremont McKenna College Claremont, CA, USA, 2018, ISSN 2366-6013 ISSN 2366-6021 (electronic) Evidence-Based Practices in Behavioral Health ISBN 978-3-319-72498-0 ISBN 978-3-319-72500-0 (eBook), https://doi.org/10.1007/978-3-319-72500-0, Pg.27

[18] Marjorie $\neg$ H. $\neg$ Charlop Russell $\neg$ Lang Mandy $\neg$ Rispoli, Play and Social Skills for Children with Autism Spectrum Disorder, Psychology Department Claremont McKenna College Claremont, CA, USA, 2018, ISSN 2366-6013 ISSN 2366-6021 (electronic) Evidence-Based Practices in Behavioral Health ISBN 978-3-319-72498-0 ISBN 978-3-319-72500-0 (eBook), https://doi.org/10.1007/978-3-319-72500-0, Pg.29

[19] Colwyn Tervarthen, Jonathan Delafield Butt, The Early development of autism spectrum disorder and its care, Autism 360,33,2019

[20] Interview withMs. Lily, AGCA Center, on November 20, 2019

[21] Interview with Ms. Nancy, Hizkia School, on November 10, 2019

[22] Helena Hartmann, Social Interactions in Autism, Cognitive Empathy, Egocentricity and Social Pain, Institut für Psychologische Grundlagenforschung und Forschungsmethoden Universität Wien Wien, Austria, 2018, ISBN 978-3-658-22012-9 ISBN 978-3-658-22013-6 (eBook) https://doi.org/10.1007/978-3-658-22013-6, Pg.97

[23] Marjorie $\neg$ H. $\neg$ Charlop Russell $\neg$ Lang Mandy $\neg$ Rispoli, Play and Social Skills for Children with Autism Spectrum Disorder, Psychology Department Claremont McKenna College Claremont, CA, USA, 2018, ISSN 2366-6013 ISSN 2366-6021 (electronic) Evidence-Based Practices in Behavioral Health ISBN 978-3-319-72498-0 ISBN 978-3-319-72500-0 (eBook), https://doi.org/10.1007/978-3-319-72500-0, Pg.86 